\title{
Ergonomics in the Box Mobile Containers as Medical Workplaces at an International Airport
}

\section{Conference Paper}

\section{Author(s):}

Held, Jürgen (D); Krueger, Helmut

Publication date:

2000-07

Permanent link:

https://doi.org/10.3929/ethz-b-000300432

\section{Rights / license:}

In Copyright - Non-Commercial Use Permitted

Originally published in:

Proceedings of the Human Factors and Ergonomics Society Annual Meeting 44(33), https://doi.org/10.1177/154193120004403345 


\title{
ERGONOMICS IN THE BOX 1 \\ MOBILE CONTAINERS AS MEDICAL WORKPLACES AT AN \\ INTERNATIONAL AIRPORT
}

\author{
Jürgen Held and Helmut Krueger \\ Institute of Hygiene and Applied Physiology \\ Swiss Federal Institute of Technology Zurich, Switzerland
}

\begin{abstract}
The management of catastrophes with a high number of seriously injured people requires a point of first medical treatment in the midst area of damage. The Firebrigade and Rescue Paramedic Team at the international airport Zurich in Switzerland is therefore developing two mobile containers as medical workplaces. It was found by the task and posture analysis, that the norm of minimum workspace dimensions for ambulances is not a practicable guideline for an ergonomic design of the container interior. The basic idea of the new concept is a turnable operating table, that guarantees an easy transfer and is furthermore a flexible solution for two different work situations, depending on the number of persons in the Paramedic Team. The project is relevant to understand and to use the catalytic impact of an ergonomic survey in design processes which different participated professions.
\end{abstract}

\section{INTRODUCTION}

\section{In the Midst of a Catastrophe}

Catastrophes or disasters, for example an aeroplane crash, can lead to a high amount of injured people. Than the objective is to transport as much as possible of the injured to the nearest hospitals. The order is:

a) At first those injured people, who can survive transportation but who need therefore immediately a medical treatment.

b) Parallel or afterwards all patients who can survive transportation without treatments.

c) Patients in a better state of health than in case b) must wait. Patients in a worst state of health than in case a) must die.

It became clear, that the treatment in case a) is under time restriction and that the emergency doctors need a place to perform their tasks. This place or room must provide equipment, devices and a kind of operation table. More than one of this room will be necessary in the midst or nearby of the disaster area.

The Firebrigade and Rescue Paramedic Team at the international airport Zurich in Switzerland has a bus with such an interior to cope catastrophes at the of date, it's a 1960 model and will have no longer the permission of use.

\section{Mobile Operating Rooms}

The idea of the airport's paramedic team is, to develop two mobile containers. One as part of a semi-trailer truck. The other as a stand alone container which can be move with a truck or an helicopter (see figure 1). Each of the both container should provide two medical work places, similarly to small operating rooms (OR's).

\section{The User's doubts}

An engineer in construction and interior design of ambulances proposed a first layout, using the technical and organisational specifications of the paramedic team. A norm already defines the minimum work space around the patient in ambulances and seemed to be helpful for the layout (DIN 75080-2, 1989). The paramedics tried to evaluate the proposed layout and built a simple prototype. A lot of questions and uncertainties arose and brought the decision makers to the point to ask ergonomists to support this project.

airport or in the surrounding area. This vehicle is out

\footnotetext{
${ }^{1}$ In: Proceedings of the IEA 2000/HFES 2000 Congress, Vol. 6, pp. 245 - 248.
} 


\section{METHOD}

1. Context analysis

- accompanying of emergency teams at work.

- inspection of hospital emergency facilities.

- inspection of interiors of ambulance cars.

2. User interviews

Semi-structured interviews with emergency doctors

and paramedics about:

- work organisation in case of emergencies.

- specification of the required tasks.

- linkage to the required equipment.

1. Detail analysis of task, postures and equipment

- observation and registration of tasks, sub-tasks and linkage to persons and equipment.

- role play and simulation of treatments, photo documentation of postures, workspace analysis.

- Specification of equipment seizes.

2. Layout conception and discussion

- Drawing of the interior design.

- Showing the plans to the users. Discussion.

3. Mock up design and test

- Construction of a mock up for one workplace: scale 1:1, real instruments and devices.

- Scenario technique and role play with paramedics, emergency doctors and a patient dummy.

\section{RESULTS}

\section{Context and interview results}

The container dimensions were given by the traffic regulations (figure 1).

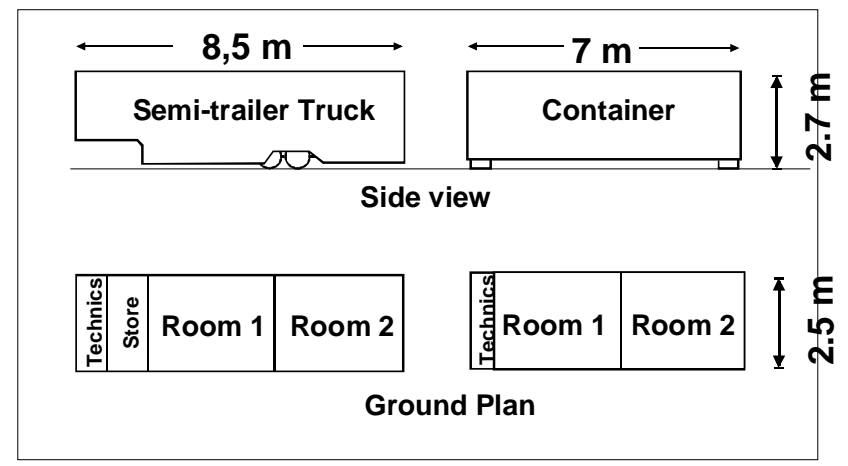

Figure 1: Dimensions of the two containers.
The key requirements for the interior are:

- work space in each OR for two and optional for three persons (one emergency doctor plus one or two paramedic team members)

- Those people who bring in the patient shall not enter the room.

- Circulation between the both container rooms must be possible for the team without leaving the container.

The tasks in order of their frequencies are:

Always:

- transfer of the patient

- checking of the injuries

- infusion, monitoring

- oxygenation, breathing,intubation

Often:

- medication, pain therapy

Sometimes:

- hemostasis

- cooling

- repositioning, fixation

Rare:

- reanimation

- thorax drain, coniotomy

- amputation, vascular ligation

- obstetics

\section{Task and Posture Analysis}

The photo documents of the role play shows several working postures. The copy withmannikins

(Pheasant, 1988) lead to the description of required workspace around the OR-table (figure 2 and 3 ).

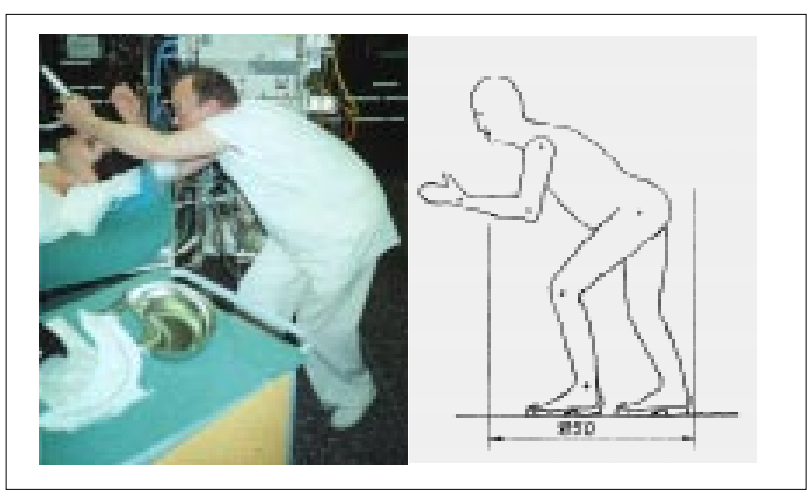

Figure 2: $\quad$ Work posture ,intubation" and the copy with 95\%ilemannikin. 


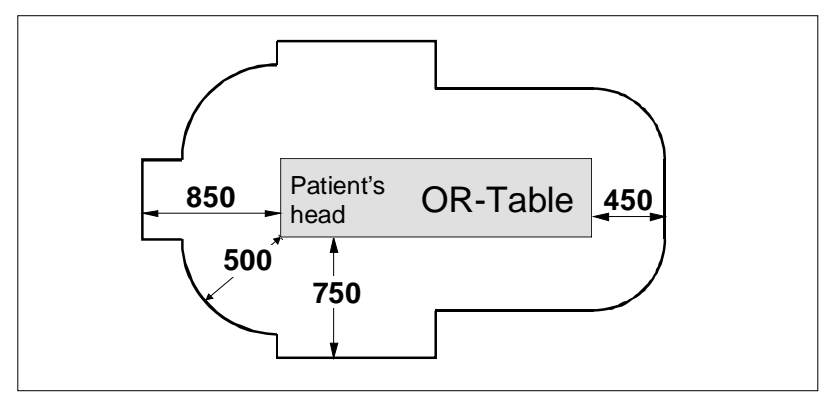

Figure 3: $\quad$ Workspace derived from task and posture analysis.

\section{Layout Conception and Discussion}

The conception went out from the OR-table and the demand to transfer the patient without entering the container. This lead to the idea, were the OR-table revolves around a fix point (figure 4).

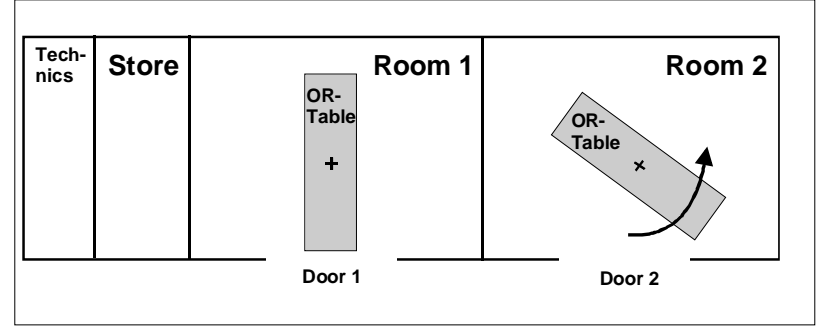

Figure 4: The turnable ORtables in the both container rooms. Turned to the door for patient transfer (Room 1) and in turn to a work position (Room 2).

The conception of the interior design was done in respect to the required work space for two and three persons. The idea is a mechanism to fix the OR-table at angles of $0^{\circ}$ and $20^{\circ}$ degree (figure 5).

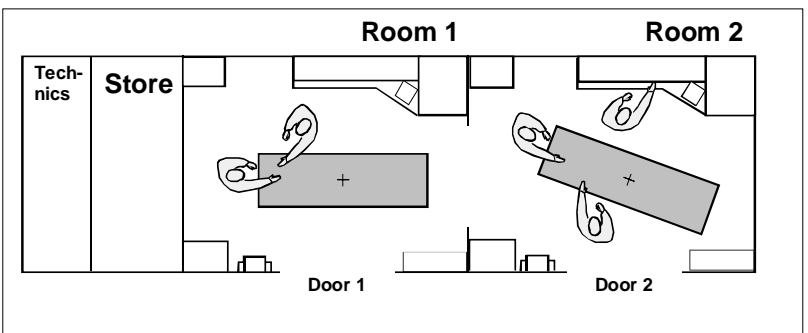

Figure 5: $\quad$ Interior ground plan and the two work positions of the OR-table.

The discussion of the proposed layout with the users leaded to further specifications for the position of devices and instruments. The monitor of vital signs is mounted on a flexible support arm. The respirator is fixed under the ceiling as well as the connections for oxygen and the plug-in connections for the monitor cables. (figure 6).

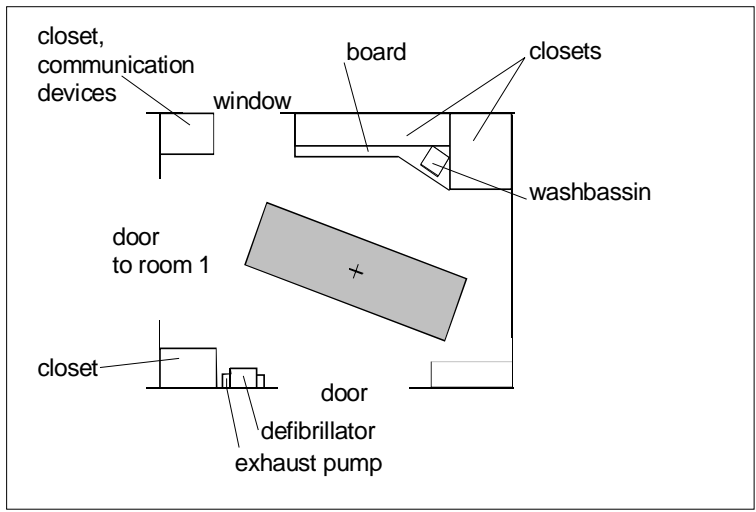

Figure 6: $\quad$ Interior parts and devices.

\section{Mock-up design and test}

The mock-up was made of simple interior elements, boards to represent the walls, a patient dummy, real instruments and devices.

The test with the users showed, that the workspace is sufficient for two as well for three persons. Positive feed back reached the evaluation of the patient handling and the dimensions of work surfaces. Improvements were discussed for the position of the monitor cable connectors and the handling of the exhaust pump.

\section{Realisation}

Both containers were realised under the regulations of this study. They are ready for use at the airport in Zurich. Usability test results and user feed back lead to satisfaction for all participants.

\section{DISCUSSION}

\section{Workspace}

The workspace derived from the task analysis differs in shape and size from the minimum workspace requirement proposed by the norm DIN 75080-2. More work space is necessary beside of the patient's thorax, at the end of the OR-table and 
especially around the patient's head (figure 7). Insufficient work space or zones of reach can detect in many work place layouts. This decreases the quality of the work place and the work. In medicine those problems are especially delicate, as quality of work is the health of the patient. In this context, the following aspects are of importance:

- When using standards: There must be a strong correlation between the user's tasks and the underlying task's of the standard.

- Scaled mannikins can only use for work place layout with the detail knowledge of the required work postures.

- Symbols or clip-arts are not suitable for layout conception. Their only use is for visualisation of work situations as shown in figure 5 .

It became clear in this project, that the users can't specify workspace requirements in the same manner as they specify the requirements of engine power for the container truck.

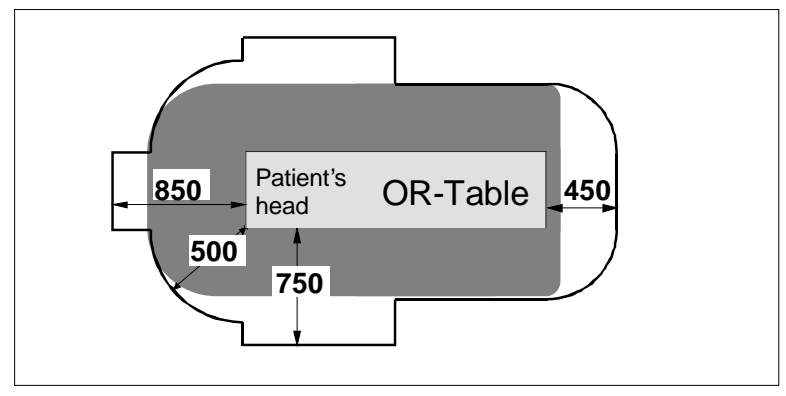

Figure 7: Workspace comparison, layout (outer line) and norm (hatched).

\section{Expert - User Interactions}

The interaction between the ergonomist and the users as experts of the work procedures is a key factor for innovation (Held \& Krueger, 2000). This means more than incorporation of user feed back from usability testing of prototypes during the design process. The point is, to transfer knowledge and to build a basis of mutual understanding in the earliest stage of the project: in the analysis. Only to observe and ask the user's to understand their needs is not enough.

The demand is a certain strategy to facilitate knowledge explication. A role play for example activate the user's imagination and releases time for problem awareness. Further is the user-oriented visualisation an important factor to reach a better understanding. For example: physicians often can't read a layout plan. Those misinterpretations causes immense problems when they rest unspoken and hidden. The challenge is, to invoke and moderate processes, where both parties will show their interpretations and co-operate with them before any problem definition or action of solving starts.

\section{Time and Costs}

No one will wait and it sounds expensive to make the analysis of a project to a project itself. But in a participatory approach as shown in this work, the more time needed for analysis is the less time needed for trial and error in prototyping. And who will redesign immediately after design? (figure 7).

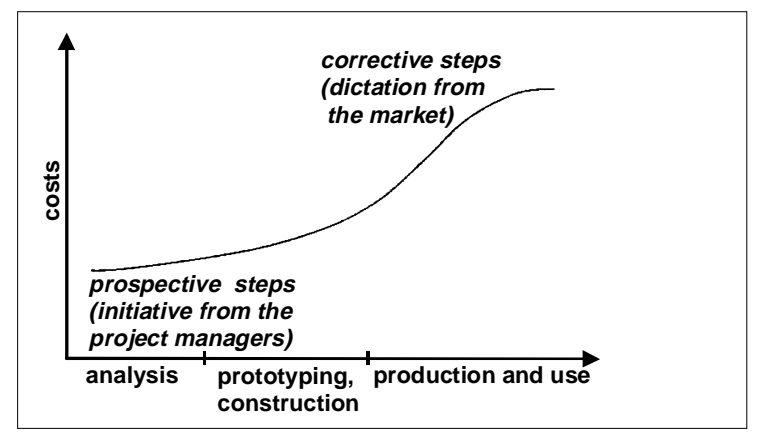

Figure 7: Costs of interventions during design.

\section{CONCLUSION}

Ergonomics and medicine has the common parole: „Don't be too late!“”, and the same risk: The fault therapy or design strategy.

\section{REFERENCES}

DIN 75 080-2 (1989). Krankenkraftwagen -

Rettungswagen Teil 2. In Deutsches Institut für Normung (Eds.), Rettungsdienst: Normen (pp. 207-218). Berlin: Beuth.

Pheasant, S. (1988). Bodyspace - Anthropometry, Ergonomics and Design. London: Taylor \& Francis.

Held, J. \& Krueger, H. (2000). In the Beginning...

Principles and the B-fore Model for Participatory Ergonomics and Design. InProc. XIVth Triennial Congress of the International Ergonomics Association. San Diego 2000. 